\title{
THE REPAIR OF DNA DAMAGE INDUCED IN HUMAN PERIPHERAL LYMPHOCYTES WITH STYRENE OXIDE
}

\author{
Renata Köhlerová ${ }^{1}$, Rudolf Štětina ${ }^{2}$ \\ Charles University in Prague, Faculty of Medicine in Hradec Králové: Department of Medical Biochemistry'; Purkyně \\ Military Medical Academy in Hradec Králové: Department of Toxicology² \\ Summary: Isolated human peripheral lymphocytes were treated in vitro with styrene-7, 8-oxide (SO) and the kinetics of \\ the repair of induced DNA damage was assessed by comet assay during further incubation of lymphocytes. Using a modi- \\ fied assay we measured simultaneously the number of single strand breaks in DNA (SSBs) and the sites sensitive to endo- \\ nuclease III (endo III) that most probably represent abasic sites in DNA molecules. SO induced DNA damage in \\ a dose-dependent manner and both SSBs and endo III sites were removed from the DNA by a repair process with a half \\ time about 2-4 hours. The damage was repaired completely within 12 hours after the treatment.
}

Key words: Styrene oxide; SSBs; DNA repair; Human lymphocytes; Comet assay

\section{Introduction}

Styrene, an extensively used industrial chemical, is classified by IACR (International Agency for Research on Cancer) as a possible human carcinogen (group 2B). It is a colourless gas with a typical biting smell. Humans are exposed to styrene from industrial and exhaust emissions, from cigarette smoke or building materials. Small quantities of styrene may evolve from polystyrene packing. Styrene is absorbed through skin, mucous membranes and airways. It induces SSBs in vivo (6). It is transformed by cytochrom P450 in the organism (1).

Styrene-7, 8-oxide (SO), the primary mammalian metabolic product of styrene, is classified by IACR as a probable human carcinogen (group 2A). SO forms adducts with DNA and nucleophilic sites of amino acids. The number of SSBs depends on adduct quantities. The most frequent adducts are in N-7 (two stereoisomeres $\alpha$ and $\beta, \mathrm{N}^{2}$ and $\mathrm{O}^{6}$-position of guanine in ratio 74:23:3.7.

The comet assay (single cell gel electrophoresis (SCGE)) is a simple, quick and relatively cheap test for the detection and measuring of damage of DNA (3). Ostling and Johanson (7) first described this method; its modification by Singh (8) is often used. This test has been used both in molecular and epidemiological studies (testing genotoxicity of different chemicals, biomonitoring of human population).

Cells analysed for the DNA damage are embedded in agarose and lysed with a detergent and high salt concentration, leaving supercoiled DNA attached to the matrix in the nucleoid. When DNA is damaged, relaxed DNA loops are pulled out of the nucleoid towards anode during the elec- trophoresis, forming a comet-like structure. The comet can be visualised by fluorescence microscopy (see Fig. 4). The fluorescence intensity in comet tail is proportional to the number of SSBs present in the DNA (3). Comets formed are mostly analysed by image analysis, which usually offers a number of comet-parameters to score. Vast majority of authors use the percentage of DNA in the tail (TD), tail length (TL) or tail moment $(\mathrm{TM})$, where $\mathrm{TM}=(\mathrm{TD} \times \mathrm{TL}) / 100$.

The first works $(7,8)$ used on agarose electrophoresis in neutral buffers. Collins et al. (3) compared the neutral and the alkaline tests. Both methods showed a low degree of DNA damage. Maximum amount of DNA in the tail is about $25 \%$ by neutral electrophoresis regardless of the degree of damage. The amount of DNA in the tail is over $90 \%$ by alkaline electrophoresis. The alkaline version is useful for distinguishing low and high DNA damage. The alkaline comet assay detects SSBs. Many genotoxic compounds do not create SSBs directly, but they may produce alkali-labile sites in the DNA molecule. These sites are able to generate SSBs in the solution with high $\mathrm{pH}$.

It is generally known that removing DNA damage is a quantitative indicator of cell repair. Temporary short-term breaks are caused by DNA repair through base excision or nucleotide excision. The high level of SSBs shows big damage or effective repair.

The first aim of this study was to find the best parameter for the determination of the DNA damage caused by SO using comet assay. The second aim was to find some endonuclease III sensitive sites in the DNA of SO-treated cells, which may appear in case the SO induced DNA damage is repaired by base excision repair (BER). 


\section{Material and Methods}

\section{Cell culture and culture conditions}

Human peripheral lymphocytes were isolated on FicollVerografin gradients and then cultured in RPMI 1640 (Gibco) supplemented with $10 \%$ foetal calf serum (Gibco) and mixture of antibiotics (Antimitotic Gibco) in a humidified incubator at $37{ }^{\circ} \mathrm{C}$ and controlled $5 \% \mathrm{CO}_{2}$ atmosphere.

\section{Cell treatments with styrene oxide}

The stock solution of SO (Fluka) was diluted with DMSO (Merck) and added to each tube with cells to give final concentrations of SO 25, 50, 100, 125, 150, 200, 250, 400,500 and $600 \mu \mathrm{M}$ and final DMSO concentration of $0.25 \%$. Control cell cultures were treated with DMSO only or they were left without treatment. After the 60 minutes treatment the medium was removed, cells were washed twice with $5 \mathrm{ml}$ PBS (Sigma), centrifuged and diluted into $0.5 \mathrm{ml}$ PBS. This cell suspension was used for the comet assay (see below). Concentrations 100 and $250 \mu \mathrm{M}$ of SO were used in the repair study. The cells were treated with $\mathrm{SO}$ as described above. After washing them twice with $5 \mathrm{ml}$ PBS they were diluted into $1 \mathrm{ml}$ fresh medium and incubated under the above conditions for $2,4,6,12$ and 24 hours. The medium was then removed, the cells were washed twice with $5 \mathrm{ml}$ PBS and diluted into $0.5 \mathrm{ml}$ PBS.

\section{Comet assay}

DNA damage was measured using the alkaline version of comet assay as described previously (4). Briefly, cells embedded in $1 \%$ agarose (Sigma) on microscope slides were lysed in $10 \mathrm{mM}$ Tris-buffered $2.5 \mathrm{M} \mathrm{NaCl}(\mathrm{pH} 10.0$; Penta) containing 1\% Triton X 100 (Merck) and $100 \mathrm{mM}$ EDTA (Penta) for 1 hour at $4{ }^{\circ} \mathrm{C}$. The electrophoresis was carried out at $25 \mathrm{~V}, 300 \mathrm{~mA}$, for $30 \mathrm{~min}$ at $4^{\circ} \mathrm{C}$ after a $40-\mathrm{mi}-$ nute period of unwinding. Enzyme endonuclease III (kindly provided by Dr Andrew Collins, Rowett Res. Inst., Aberdeen, UK) was added to the parallel slides to detect oxidized bases or abasic sites after lysis according to Collins et al. (3).

\section{Statistical evaluation}

DNA damage was analysed by the comet module of Lucia G image analysis (Laboratory Imaging, Prague, Czech Republic) after staining the cells with $2 \%$ ethidium bromide (Sigma). The image analysis enabled measuring different parameters of comet cells. We compared three of those parameters: the percentage of DNA in the comet tail (TD), length of tail (TL) and tail moment (TM). TM calculation is also based on TL $(\mathrm{TM}=(\mathrm{TL} \times \mathrm{TD} / 100)$. SSBs was calculated by Collins et al. (3). Twenty-five cells per slide were analysed. Values in the graph are averages from three independent experiments with suitable standard deviations.

To determine the dependence of parameters TD, TL and TM on concentration, Linear Regression Model (LRM) has been used and computed fraction of variance explained by the model $\mathrm{R}^{2}=1-\Sigma\left(\mathrm{R}[\mathrm{i}]^{2}\right) / \Sigma\left(\left(\mathrm{y}[\mathrm{i}]-\mathrm{y}^{*}\right)^{2}\right)$, where $\mathrm{y}^{*}$ is the mean of $y[i]$ if there is an intercept and zero otherwise, $\mathrm{R}[\mathrm{i}]$ is the $\mathrm{i}$-th residual. The non-parametric Mann-Whitney U-test (Sigmastat 2.0) was used for the analysis of difference between two aggregates while the non-parametric Kruskal-Wallis test was used for the multifactorial analysis of variance of particular comet parameters TD, TL and TM. All parameters were expressed as per cent of the mean of TM measured after the most effective dose $(400 \mu \mathrm{M})$.

\section{Results}

\section{Induction of the DNA damage}

After treating sets of tubes containing incubated lymphocytes with different concentrations of SO for $60 \mathrm{~min}$, the comet assay was carried out. The results of these experiments are shown in Figure 1. The image analysis allows measuring different parameters of comet cells. We compared three of those parameters: TD, TL and TM (see Fig. 1 $\mathrm{B}, \mathrm{C}$, and D). We examined which of these parameters is the most suitable one for describing DNA damage. We used LRM and computed $\mathrm{R}^{2}$ coefficient. We can see that the value $\mathrm{R}^{2}$ for TD is the biggest (see Tab. 2). This means that the degree of linear dependence of TD on concentration is higher than the degree of linear dependence of both TL and (TM) on concentration. TD (Fig. 1 B) reflects more precisely the DNA damage. It also shows lower variability compared to TL (Fig. 1 C, Tab. 1), which may also be affected by the background fluorescence, especially when the cell damage is low. TL reaches a plateau at low doses as well, with no further remarkable changes. Implicitly, TL, showing high variability, also affects the parameter TM. Similarly to TL, variability of TM is significantly higher compared to TD (see Tab.1). This is why we chose TD as a parameter for the calculation of the number of SSB (3).

Fig. 1 indicates that SO induced significant amount of DNA breaks at concentrations $50 \mu \mathrm{M}$ and higher. There was no increase in the number of SSBs in cells treated by concentrations from 100 to $200 \mu \mathrm{M}$. The maximum amount of DNA breaks was achieved at $400 \mu \mathrm{M}$ (up to $4 \mathrm{SSBs} / 10^{9}$ Daltons), which represents the upper limit of the comet assay modification used in this study.

As shown in Fig. 2, there was smaller difference in the number of SSB in cells treated for 30 or $60 \mathrm{~min}$.

\section{DNA repair}

Lymphocytes in culture were treated with two doses selected on the basis results of the previous experiment ( 100 and $250 \mu \mathrm{M}$ ). The initial DNA damage of the cells treated with SO is dose-dependent (see Fig. 3). Further incubation of cells after the 1-hour treatment showed that the low dose induced damage of DNA $(100 \mu \mathrm{M})$ is partially repaired 4 hours after treatment. The high dose $(250 \mu \mathrm{M})$ induced a damage of DNA, which was partially repaired even earlier - after 2 hours. Both low and high dose damages of DNA were nearly repaired 12 hours after the treatment. 

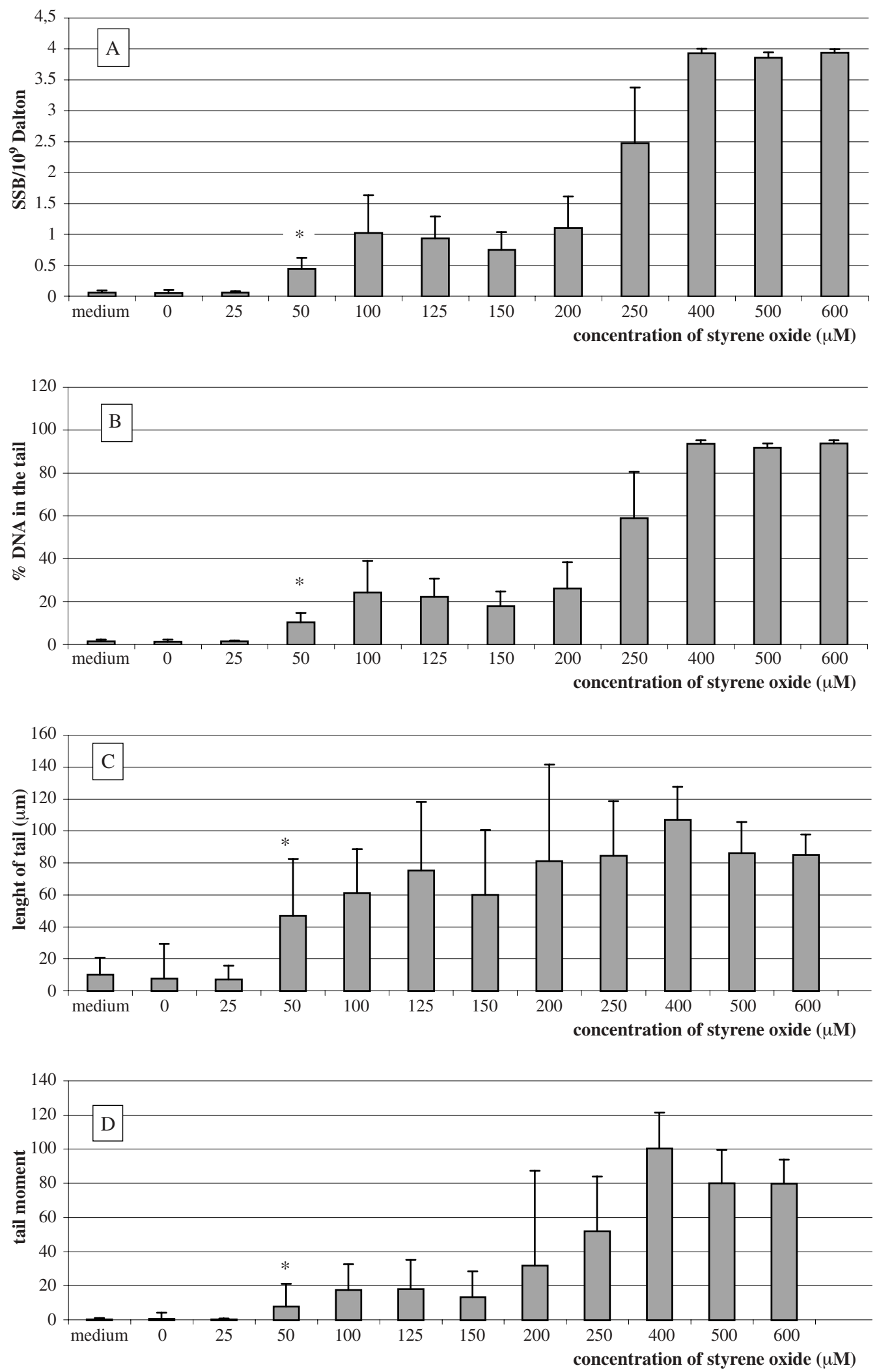

Fig. 1: The dependence of three parameters of DNA damage and SSB on the concentration of styrene oxide. Asterisk indicate the values significantly different from the control (distinguished using Mann- Whitney U-test). 
Tab. 1: Comprehensive results of statistical analysis. All parameters were expressed as per cent of the mean of TM measured after the most effective dose $(400 \mu \mathrm{M})$. N - number of measured cells.

\begin{tabular}{|c|c|c|c|c|c|c|c|c|c|}
\hline \multicolumn{2}{|c|}{ concentration } & \multicolumn{2}{c|}{ \% tail DNA } & \multicolumn{2}{c|}{ tail length } & \multicolumn{2}{c|}{ tail moment } & \multicolumn{2}{c|}{ Kruskal-Wallis test } \\
\cline { 3 - 10 } uM SO & $\mathrm{N}$ & mean & SD & mean & SD & mean & SD & H & P \\
\hline 0 & 125 & 1.101 & 3.454 & 8.037 & 23.348 & 0.564 & 3.672 & 60.25 & $<0.001$ \\
\hline 25 & 100 & 1.353 & 3.168 & 7.435 & 9.180 & 0.220 & 0.676 & 92.18 & $<0.001$ \\
\hline 50 & 125 & 9.730 & 11.921 & 50.014 & 38.213 & 7.879 & 13.179 & 126.61 & $<0.001$ \\
\hline 100 & 200 & 22.684 & 16.638 & 65.076 & 29.529 & 17.236 & 15.328 & 277.56 & $<0.001$ \\
\hline 125 & 100 & 20.744 & 15.521 & 80.140 & 46.107 & 18.153 & 17.060 & 135.28 & $<0.001$ \\
\hline 150 & 100 & 16.543 & 13.401 & 63.887 & 43.448 & 13.166 & 15.335 & 98.09 & $<0.001$ \\
\hline 200 & 100 & 24.428 & 22.239 & 86.407 & 64.969 & 31.972 & 55.764 & 101.84 & $<0.001$ \\
\hline 250 & 225 & 54.950 & 24.380 & 89.819 & 36.466 & 51.630 & 31.894 & 138.26 & $<0.001$ \\
\hline 400 & 100 & 88.172 & 6.066 & 114.033 & 22.103 & 100.000 & 21.282 & 99.28 & $<0.001$ \\
\hline
\end{tabular}

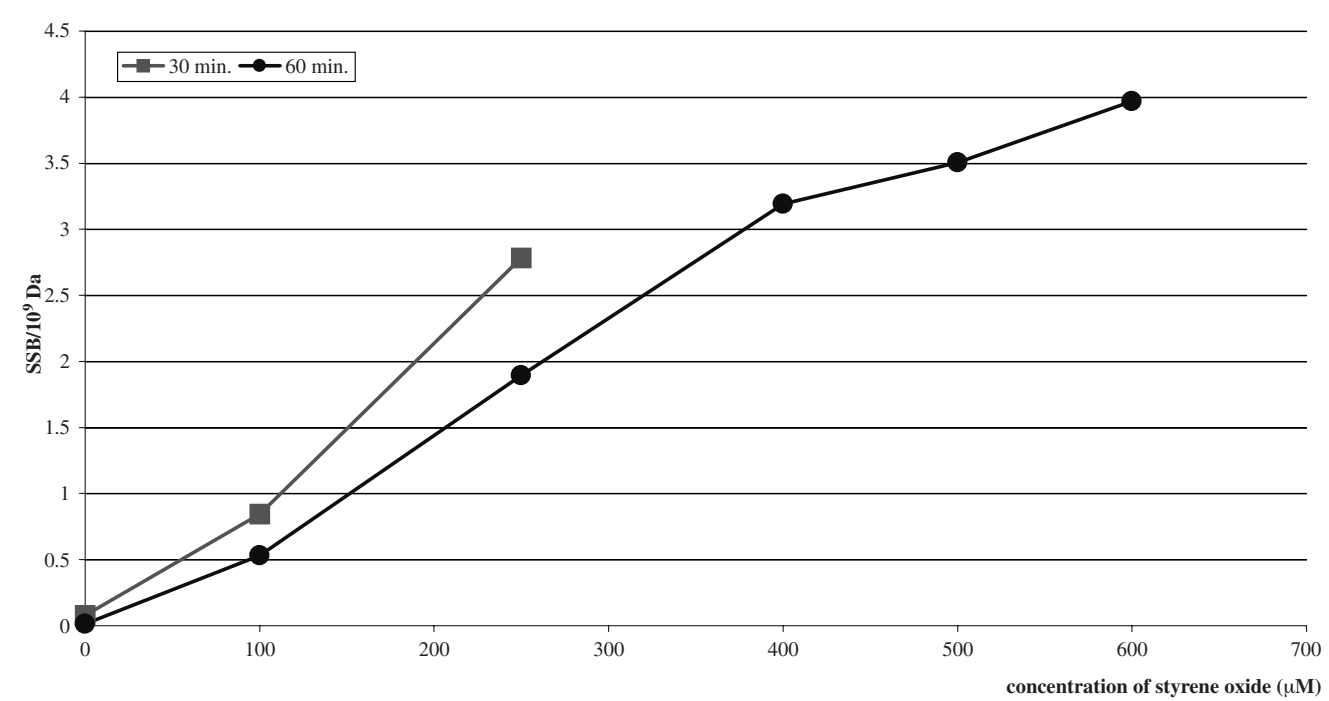

Fig. 2: The change in the number of SSBs depending on the concentration with two different times of incubation with styrene oxide.

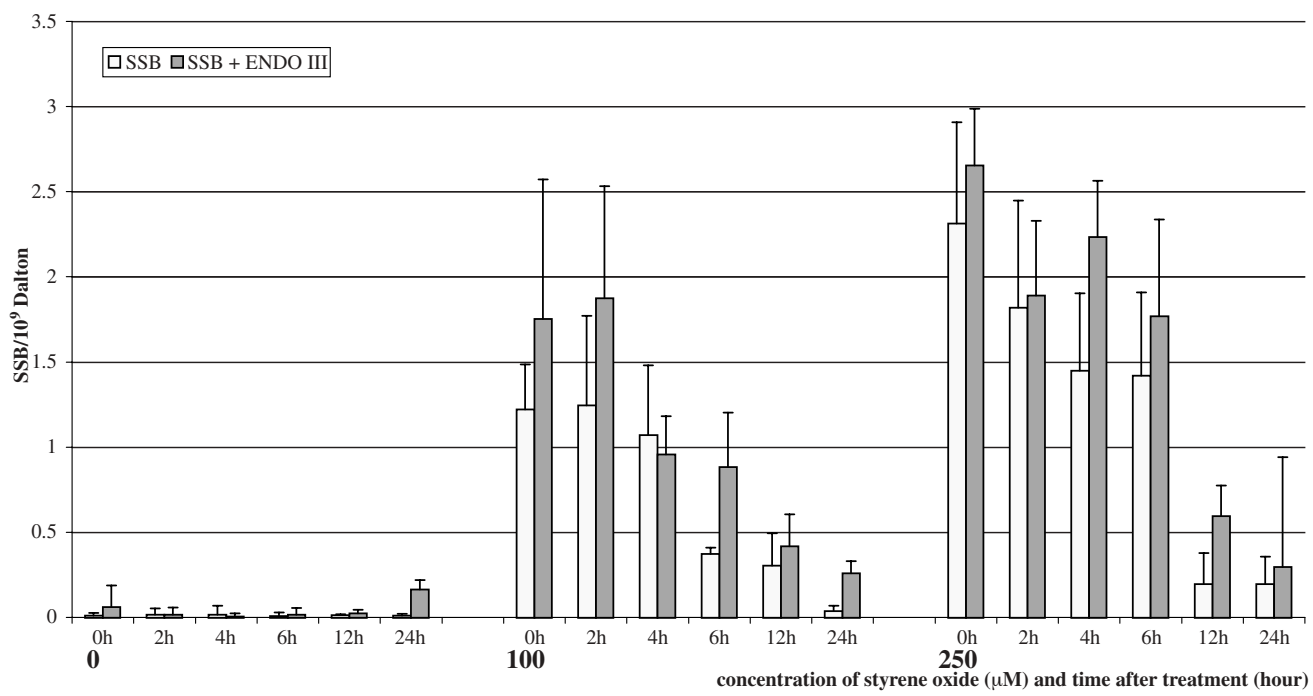

Fig. 3: The change in the number of SSBs depending on the concentration of SO and on the time of repair. 


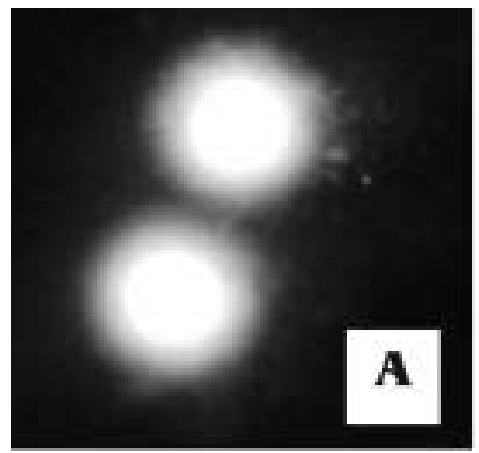

Fig. 4: Digital camera photograph A) undamaged cells

B) damaged cells - comets

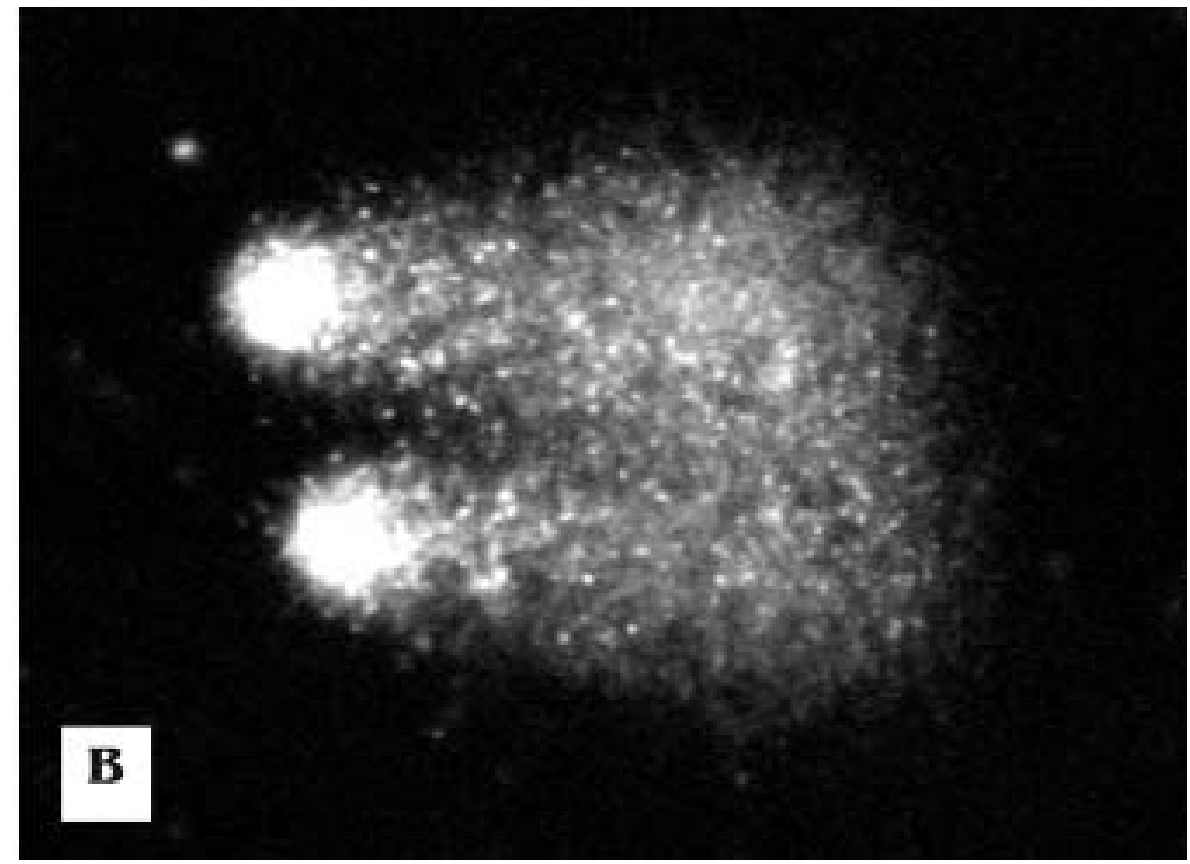

Tab. 2: Comparison of fraction of variance computed by the Linear Regression Model $\left(\mathrm{R}^{2}\right)$ for all three parameters.

\begin{tabular}{|c|c|}
\hline Parametr & $\mathrm{R}^{2}\left(\mathrm{P}<2.10^{-16}\right)$ \\
\hline TD & 0.7391 \\
\hline TL & 0.2482 \\
\hline TM & 0.5576 \\
\hline
\end{tabular}

When the cells were treated with endonuclease III before their lysis, an increase of SSBs was found (see Fig. 3). This increase (compared to parallel slides without the endonuclease III treatment) probably represents apurinic sites, which may appear during the repair of SO-induced adducts with guanine. The increase of SSBs (representing endo III sites) was up to $25 \%$ and was highest 4 to 6 hours after the treatment.

\section{Discussion}

Styrene oxide induces DNA damage at the concentration of $50 \mu \mathrm{M}$ and higher. This is in accordance with our previous findings (9). In contrast to our results, Laffon et al. (5) did not find significant damage after treatment with this concentration. The low differences between damaged and control cells found in the experiments of these authors were probably caused by different conditions of experiments, especially by the short time of alkaline unwinding (Laffon used 20 minutes while we use 40 minutes).

TD appears to be the most appropriate parameter for the evaluation of DNA damage by comet assay. Of the three variables, it best characterizes the differences between low, medium and high concentration of SO. Besides that, it is less sensitive to the conditions of electrophoresis. The other two parameters, i.e. TL and TM, show higher variability. TL grows to some limit length, then the length of tail stops growing with increasing damage; the DNA moves only from head to tail. TL shows nearly no increase over the large scale of doses of SO (from $50 \mu \mathrm{M}$ up to $250 \mu \mathrm{M}$ ) in our experiments. TL is strongly dependent on the actual conditions of electrophoresis (temperature of electrophoretic buffer, fluctuating tension-potential, localisation slide in the tank etc.) and fluorescence of gels on the background. While TL in comets can be affected by tens of per cent by high background fluorescence of the gel, TD is changed only in the order of units. Therefore, the variability of TM is also strongly affected by the variability of TL. Because TD is a relative value, it is not affected by a size of cell and the DNA damage in different cells from different tissues can be compared. This is why we prefer TD for the calculations of SSB DNA $/ 10^{9}$ daltons. This conversion of comet assay parameter to number of SSBs enables comparison with literary data concerning SSB, which were in the past usually measured by other methods, like alkaline filter elution, alkaline unwinding, alkaline sucrose gradients etc.

Laffon et al. (5) showed that TL characterizes cell damage better than TD. However they did not present the data for both TL and TD. The results of their experiments show some threshold value, at which the damage becomes apparent. Our experiments confirmed the finding that the cell damage caused by SO does not significantly depend on the time of treatment. We got similar results using both times of treatments ( 30 and 60 minutes). This may mean that there exists a balance between the induction and the repair of the DNA damage during the first hour of the treatment.

For the DNA repair experiments we have chosen the concentrations $(100 \mu \mathrm{M}$ to induce smaller damage and 
$250 \mu \mathrm{M}$ for a higher effect), at which the cell is able to repair the DNA damage. Cells repaired the lower dose after 6 hours, the higher dose after 12 hours. The low number of SSBs after 6 hours increased significantly if endonuclease III was added. It is probable that endonuclease III detects apurinic and apyrimidinic sites, which are known to be intermediate stages of BER. It still remains to be elucidated, whether the BER is active in the SO-induced DNA damage.

\section{Conclusions}

Our experiments show the percentage of DNA in the comet tail to be the best parameter of the DNA damage. It is a relative value approaching linear progression, which can be calculated as SSBs. This enables comparison of results obtained by various methods.

SO damages DNA even at concentrations as low as 50 $\mu \mathrm{M}$. The concentrations of $400 \mu \mathrm{M}$ and higher have a cytotoxic effect on human lymphocytes. DNA breaks induced with SO are removed from the DNA in a repair process with a half time about 2-4 hours. This repair process included the transient appearance of abasic sites, that may be formed spontaneously from the adduct of SO with N7-guanine, or by the action of a specific glycosylase. These abasic sites were detected in our experiments by endonuclease III.

\section{Acknowledgments}

This study was supported by grant No. 313/99/1460 from Grant Agency of Czech Republic.

\section{References}

1. Bastlova T, Vodicka P, Peterkova K, Hemminki K, Lambert B. Styrene oxide-induced HPRT mutations, DNA adducts and DNA strand breaks in cultured human lymphocytes. Carcinogenesis 1995; 16:2357-62.

2. Bastlová T. Studies on Mutagenesis by Ethylene Oxide and Styrene Oxide in the hprt Gene in Human Cells (Dissertation). Novum, Sweden: The Karolinska Institute, 1996: 74pp.

3. Collins AR, Dobson VL, Dušinská M, Kennedy G, Štětina R. The comet assay: what can it really tell us? Mutat Res 1997;375:183-93.

4. Collins AR, Dušinská M, Gedík CM, Štětina R. Oxidative damage to DNA: do we have a reliable biomarker? Environ Health Perspect 1996;104;Suppl 3):465-9.

5. Laffon B, Pásaro E, Méndéz J. DNA damage and repair in human leukocytes exposed to styrene-7,8-oxide measured by the comet assay. Toxicol Lett 2002; 126:61-8

6. Norppa H, Sorsa M. Genetic toxicity of 1, 3-butadiene and styrene. IARC 1993;127:185-93.

7. Ostling O, Johanson KJ. Microelectrophoretic study of radiation-induced DNA damages in individual mammalian cells. Biochem Biophys Res Commun 1984;123:291-8

8. Singh NP, McCoy MT, Tice RR, Schneider EL. A simple technique for quantitation of low levels of DNA damage in individual cells. Int J Radiat Biol 1988;62:184-91.

9. Vodicka P, Stetina R, Kumar R, Plna K, Hemminki K. 7-Alkylguanine adducts of styrene oxide determined by ${ }^{32} \mathrm{P}$-postlabelling in DNA and human embryonal lung fibroblasts (HEL). Carcinogenesis 1996;17:801-8.

Submitted January 2003.

Accepted May 2003.

Mgr. Renata Köhlerová,

Charles University in Prague, Faculty of Medicine in Hradec Králové, Department of Medical Biochemistry, Šimkova 870, 50038 Hradec Králové,

Czech Republic. e-mail:kohler@lfhk.cuni.cz 